\title{
3 Contextual Main Changes and Influences on the Company and Its Stakeholders
}

\section{Approach to the Changing Business Environment}

A company's foundation, development, performance, and sustainability are influenced decisively by the business environment. For this reason, the environment's evolution is very important for all companies and should be analyzed in depth and its changes are taken into consideration carefully.

The business environment includes an organization's all exogenous elements of a different nature - technical, economic, demographic, cultural, scientific, ecologic, political, medical, legal, etc. - that influence the prevision of the objectives, obtaining the resources, the decision-making, and implementation in order to be performant. The main categories of factors that can be separated into business environment or company environment are as follows:

- Economic factors (domestic market, international market, banking system, inflation, exchange rate, population incomes, etc.);

- Technical and technological factors (digital technologies, available machinery and equipment, number and quality of licences and patents, potential of R\&D branch, etc.);

- Management-administrative factors (national strategy and policy, quality of the central and local administration, available managerial systems, methods and techniques, quality of management consultancy and training, e.tc.);

- Demographic factors (population number and its socio-professional structure, share of occupied population, birth rate, mortality rate, etc.);

- Sociocultural factors (social structure of the population, educational system, health system, national culture, etc.);

- Medical factors (health system, pandemic disease, drugs, etc.);

- Ecological factors (natural resources, climate, water, vegetation, fauna, etc.);

- Political factors (national policies [economic, social, educational, science, etc.], international bodies' policies [United Nations, 
International Labour Organization, International Monetary Fund, Word Bank, etc.], policies of the most powerful countries [USA, China, Russia, Germany, etc.]);

- Legal factors (business laws, governmental decisions, quality of judiciary bodies, etc.).

The intensive internationalization during the last few decades has determined an increase in the impact of environmental factors from outside countries on companies, their activities, and performances. Without any doubt, the last hundred years have been characterized by the numerous and profound changes in all environmental factors. The COVID-19 pandemic - a medical factor - is the last major change that has caused many and important shifts in all components of the business environment. COVID-19 has influenced to a large extent the manifestation of the majority of the other eight categories at least in the short and medium term. Never, in the history of mankind, have changes been so comprehensive, fast, and intensive.

In this chapter, we focus on the global changes in the business environment, generated to a large extent by the transition to a knowledgebased economy and by digitalization. Our analysis has revealed that, in the context of the transition to a knowledge-based economy, of the persistence of specific elements of the capitalist economy and society and - in the less developed areas - of the previous socio-economic systems, we can identify certain essential trends in the organizational environment at the world level: so-called "megashifts".

We will present the main megashifts identified by us starting from the consultation of a large number of studies (Attali, 2007; Brătianu, 2015; Broadman, 2015; Brown, Adams, Larsen, \& Roney, 2015; Griffin, 2012; Lichtenthaler, 2016; Markoff, 2016; Naqvi, 2014; Nicolescu, Popa, Nicolescu, \& Ștefan, 2019; Nicolescu et al., 2019) and based on our own analysis.

The background of the megashifts is represented by the intensification, diversification, and acceleration of innovation. Numerous papers (Birkinshaw, Hamel, \& Mol, 2008; Burkus, 2013; Christensen, Raynor, \& McDonald, 2015; Grossman, 2016; Hamel, 2006; Pisano, 2015) have proved that innovation represents the engine of the revolutionary changes taking place in all fields of society. The trends presented in the following sections represent the essential innovations developing in the business environment at the global level that predominantly influence an organization's activities, functionality, and performance (see Figure 3.1).

The environmental tendencies influence companies in many areas:

- Company inputs (knowledge, information, raw materials, energy, human resources, product and service demands, machines, equipment, credits, etc.). 


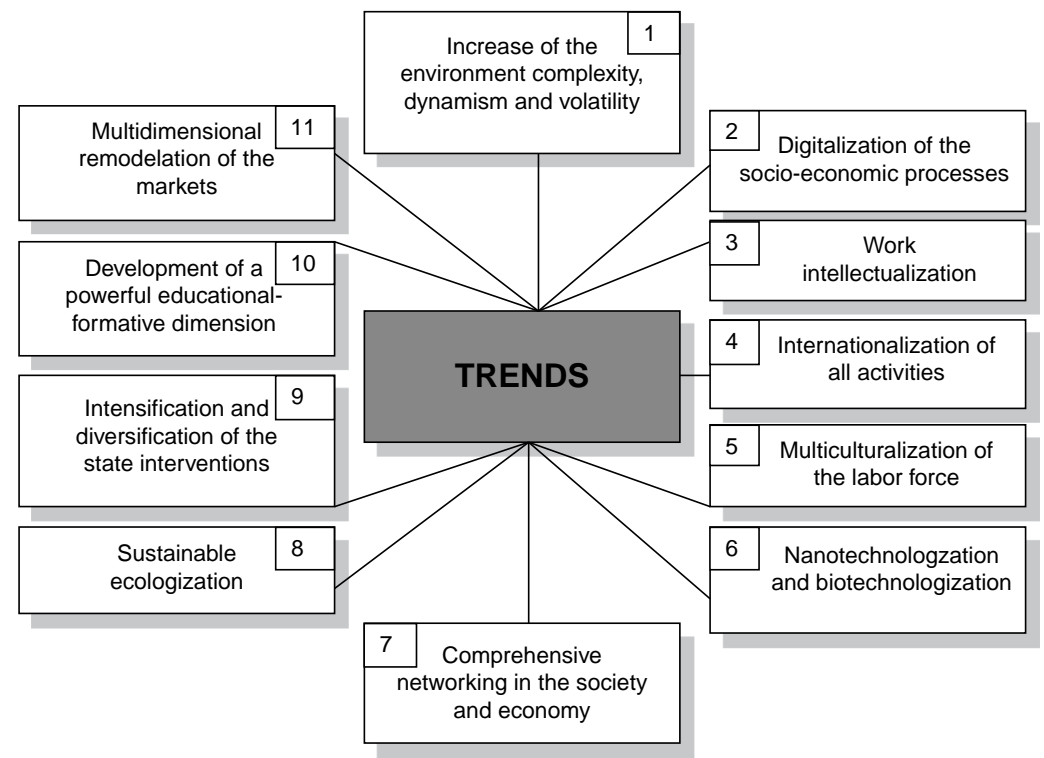

Figure 3.1 The main trends - "megashifts" - in the organization changing business environment.

- Company activities and works (content, structure, duration, quality, cost, etc.)

- Company outputs and performances (products, services, turnover, productivity, market share, profit, dividends, competitive advantage, sustainability, etc.)

Bearing in mind all these influences, we will indicate in the following sections some of the most influential mutations in the global business environment that should be taken into consideration by companies' management in order to achieve competitive advantage and sustainability. We will try to approach each of the tendencies identified and analyzed according to the elements incorporated in Figure 3.2.

The changes in the global business environment heavily influence not only companies but also national economies and the world economy. Their effects and influences are interrelated on multiple levels, increasing the difficulty of their perception and of performant feedback from all types of entities. In order to face these challenges, to stop the negative effects and to valorize the opportunities, global approaches have been developed through international organizations - United Nations Organization (UNO), International Labour Organization (ILO), World Trade Organization (WTO), International Monetary Fund (IMF), World Bank (WB), etc. The above-mentioned organizations and other 


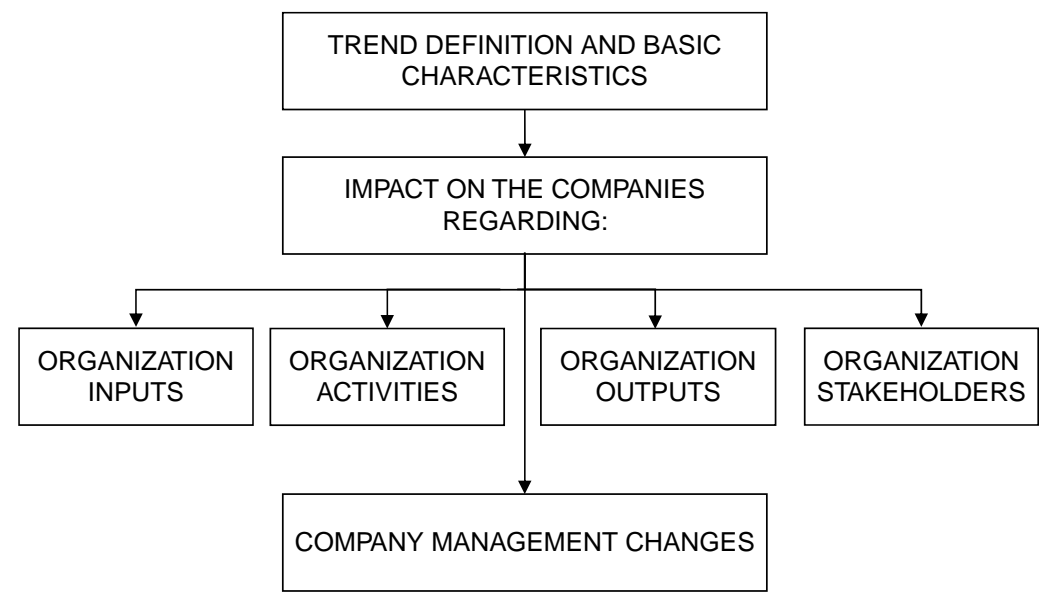

Figure 3.2 Main elements regarding the approach of the business environment trends.

international bodies have developed strategies, agreements, protocols, resolutions, and recommendations regarding future global evolutions or in certain major fields - trade, finance, labour force, banking, ecology, military, and others - trying to contribute to better activities and performances at all levels (international, national economies, and companies).

Without any doubt, the COVID-19 pandemic is the contextual element with the most influential impact on the business environment in this period. It has multiple very intense and often unexpected influences on the society and economy, compared with megashifts that occurred in the last few decades.

We consider it necessary to make two remarks regarding the approach to the changes generated by the COVID -19 pandemic in the business environment:

a In the present and next period, the COVID-19 pandemic produces, and will continue to produce, substantial changes that shock us, providing major threats to, and difficulties in, the economy and society, concomitantly with some opportunities. However, the direct impacts of the pandemic will decrease gradually in the next few years, because of the diminution of the pandemic's intensity and because the management of various entities (state, region, company, etc.) will learn how to face the pandemic and its effects.

b Manifestations of all megashifts are influenced by the COVID-19 pandemic, quite often notably so. We consider it useful to make the point that all the megashifts mentioned above will continue to 
operate in the future, because their roots are in the objective evolution of the economy and society. In our approach, we shall try, at the level of each megashift, to reveal some of the pandemic's influences that are closely conected with the objectives and problems of our book.

\section{Main Trends in the Changing Business Environment}

\section{Increase in the Business Environment Complexity, Dynamism, and Volatility}

During the last century, the organization business environment changed very fast and intensely. Recently four major changes in the business environment were proposed in a new concept known as VUCA - volatility, uncertainty, complexity, and ambiguity (Bennett \& Lemoine, 2014; Garrow \& Varney, 2015). We adopt a partially different approach in considering that the relevant mutations in the business environment are complexity, dynamism, and volatility.

Complexity means that the business environment incorporates numerous elements and their numbers increase rapidly; the size, nature, and dynamics of these elements are diversified, and the interrelations among components are rapidly amplified. There is a vast amount of information and knowledge about the majority of business components, but some of them are difficult to understand and time-consuming for analysis, prediction, and decision-making. The number of variables and the interrelationships among them, which should be analyzed and taken into consideration by management bodies, are huge and rapidly increasing.

Dynamism means that a large proportion of the business environment components are moving very fast. The most rapid are changing the technical elements, especially those connected with digitization, digitalization and digital transformation. This is a major reason why it is very difficult to measure and evaluate precisely the characteristics of the environmental factors and components. Anticipating their evolution is even more difficult, and the probability of getting reliable information and knowledge on these dynamic elements quite frequently is not very high. In this situation, the design of strategies and policies for the environment components becomes more difficult, with negative consequences for their quality and efficacity. Also, the implementation of the entities' strategy and policies faces many challenges and difficulties, involving a lot of rapid changes that are not easy to manage properly.

Volatility is mainly a consequence of the previous two environmental characteristics. In essence, volatility means that the environmental elements are very unstable and their evolution is quite often unexpected. The instability of the environmental factors makes it very difficult to catch them and to evaluate their parameters. Also, the unexpectedness of 
the environmental factors and their characteristics often surprises managerial bodies, finding them not ready to copy with the situations and to generate efficient solutions. Both instability and unexpectedness are generated by the actions of some variables that are not known, or not sufficiently well known, frequently without a history record. Quite often the variables are strongly related to innovation, especially to disruptive innovation. Information regarding the variables is fragmented and not sufficiently reliable, making it difficult to identify correlations and to achieve rigorous analysis.

For an organization's management the environmental volatility creates risk situations, making the decisional processes and operational activities very tough, and decreasing the company's performance and sustainability.

The others two components of VUCA - ambiguity and uncertainty we do not consider as being characteristic of the business environment, at least in the manner explained by these authors: "ambiguity characteristics: cause relationships unclear. No precedents exist, you face unknown unknowns" (Bennett \& Lemoine, 2014, p. 27). These explanations refer in fact not to characteristics of the environment but to our capacity to identify and analyze causal relationships in a complex, dynamic and volatile environment. It is obvious that causal relationships exist in the environment. Also, we do not believe that uncertainty is a characteristic of the environment. It is exactly the same situation as for ambiguity.

The complexity, dynamism, and volatility in the business environment influence organizations mainly on three levels:

- organization inputs - much of the information and knowledge, and many clients' demands, etc., are entirely new, sometimes unexpected, and for the other inputs partially changed (inflation rate, exchange rate, raw materials, machines, people, laws, etc.);

- organization activities and works - which are impacted by new commercial, financial, human, technical, etc. variables, often not sufficiently well known;

- organization outputs - which should be very frequently modified, although it is not always very clear how, in order to respond to the changing conditions of the markets, competitors, bankers, community, investors, etc.

The increase of the environment's complexity, dynamism, and volatility has several impacts directly on the stakeholders:

- all stakeholders, both internal and external, need to make more efforts and be more innovative, in order to face the environmental changes; 
- the number and importance of the company's external stakeholders will increase, involving more time and resources to cultivate the relationships with them and to valorize the new opportunities associated with them;

- the stakeholders' feedback should be faster than in the previous periods, because of the higher environmental dynamism and volatility.

Great efforts should be made by organizations' managers, shareholders, employees, and other stakeholders in all these processes, involving very diversified and high competences.

The COVID-19 pandemic influences especially the complexity and volatility by increasing their intensity. This makes it more difficult to conduct performant management in an organization and to construct and develop productive and durable relationships with all major stakeholders.

\section{Digitalization of the Socio-Economic Processes}

The digital revolution is - without any doubt - one of the most important and influential megashifts of the present times. As we have already indicated in Section 2.8 of the previous chapter, the digital revolution mainly involves three processes: digitization, digitalization, and digital transformation (Unruh \& Kiron, 2017). Their effects on the economy and society are multiple and profound. However, there are renowned specialists - like Rifkin (2016) - who believe that the evolution of digitalization has barely begun its course and that its new configuration in the form of the Internet of Things represents the next stage of development. Digitalization is very closely connected with other revolutionary technologies - artificial intelligence, big data analytics, cloud computing, 3D printing, etc.

Digitalization - like informatization previously - presents significant variation in intensity, content, and effects worldwide. Of course, in the most developed countries digitalization is at the forefront, but many other countries are rapidly recovering. Because of digitalization, the quantity of information, the information storage capacity, the degree of information processing, and the circulation speed have made huge progress in a very short time. The identification, codification, circulation, use and valorization of information, and knowledge - two of the most valuable resources in the present times - are increasing very fast. Digitalization and informatization profoundly change the content of all activities and of the socio-economic entities in which they are achieved.

Digitalization frequently renders business models and processes obsolete. Many value chains are being transformed by digital technology, some of them evolutionary, some of them disruptive (Schweer \& Sahl, 2017). At the societal level, in order to capitalize more on 
digitalization it is necessary - as very well argued by Unruh and Kiron (2017) - to promote digital transformation with the purpose of "leading the world toward a better digital future". It requires proactive scanning of the emerging landscape for both social and environmental risks, while simultaneously looking for opportunities to use digital technologies to resolve global challenges. In the European Union, the Commission has already prepared a roadmap of the digital transformation that contains five parts: change management, intent and priorities, responsibilities and skills, vision, and - last but not least - the age of the consumers.

For companies, it is recommended to have a proactive approach to facing digitalization, not the reactive approach that is still predominant today. Company management is necessary to take into consideration both positive and negative digitalization effects. Digitalization provides many advantages for companies:

- more new product and services,

- high potential digital technologies,

- faster and more efficient information and knowledge flows,

- digital interconnectivity,

- easier access to potential clients and to markets.

Concomitantly, digitalization generates many challenges and risks for companies: profound changes in customers' demands, obsolescence of products, services or technologies, major changes in human resources skills and behaviours, need for large investments, etc.

Digitalization greatly influences companies at three levels:

- inputs, affording a company rapid access to a large amount of knowledge and information, contributing greatly to the modernization of its technologies and equipment, and helping the organization to construct and to be part of networks with external and internal stakeholders;

- activities, the speed of all the company's decisional and operational processes is higher, the quantity of knowledge and information available is much larger, the capacity of each organizational field to approach and solve problems is higher;

- outputs, generated by the company through participation in digitalization - quality, turnover, productivity, incomes - are higher.

Digitization, digitalization, and digital transformation influence company stakeholders, essentially, in the following ways:

- appearance of new company stakeholders - informatics companies, digital consultants, digital designers, etc. - which are specialized in providing digital means, approaches, and solutions to organizations; 
- stakeholders' capacity to receive, process, and use information increases and speeds up;

- all stakeholders' decisions, actions, and behaviours change to a certain extent, because of the digital techniques and technologies utilized in their work;

- increase in all company stakeholders - internal and external networking among themselves and in the company involved;

- increase in information and knowledge use by, and impact on, all company stakeholders, due to digitalization and digital transformation.

It is obvious that the digital trend manifests a strong amplification and acceleration in recent years, which, without any doubt, will continue in the next period. Threats and difficulties generated by the COVID-19 pandemic provide new incentives for accelerating the development of digitalization and its use in organizations all over the world. Company managers and other stakeholders should strive - using a proactive approach - to cope as well as possible with the opportunities, challenges, and risks generated by digitalization.

\section{Work Intellectualization}

The proliferation of intellectual work processes represents one of the most challenging mutations that have occurred in the last half century in the socio-economic organization environment.

Work intellectualization incorporates mainly information processes and knowledge processing without using - or at least using minimally human physical effort. The main "tools" used are the human brain, informatics and automatized or robotic equipment.

Work intellectualization is expanding very rapidly in all countries. The USA was the first country in the world, from around 1957, where intellectual work became predominant, overcoming physical work, with the number of white-collar employees surpassing the number of blue-collar workers. Today, the digital revolution and the proliferation of new technologies - robotics, Internet of Things, artificial intelligence, drones, 3D printing, big data metrics, cloud computing, etc. - generate more intellectual work in all organizations. These technologies are based mainly on the use of more and more sophisticated and productive knowledge. The human resource, which is involved in intellectual work processes, is represented by knowledge workers. They possess intellectual capital and they work collaboratively.

Work intellectualization radically changes the coordinates and the parameters to be taken into consideration by every human being and organization, generating multiple shifts in the relations among all 
systems involved. Work intellectualization focusing on knowledge use, sharing, and valorization generates much higher productivity compared to the previous period. Because of this, intellectualization will determine profound changes in human life and the activity of organizations, facilitating the enhancement of living standards and socio-economic development in every country.

Work intellectualization has significant impacts on companies regarding:

- inputs - the quality of human resources is much better and more intellectualized, human resources have huge potential to valorize knowledge and information, to be innovative;

- activities - the knowledge and information used by intellectualized human resources in the fulfilment of each activity are greater and the quality of analysis and solutions is better, increasing the efficiency of activities;

- outputs - products and services generated by work intellectualization are richer in knowledge, their quality is higher, and they are better correlated with the market demand.

Work intellectualization also influences companies' stakeholders in several ways:

- significant increase in all stakeholders' knowledge and intellectual capital;

- improvement of all stakeholders' work quality and productivity;

- enhancement of stakeholders' capacity to understand, to analyze, and to design solutions for new individual and organizational challenges, opportunities, and threats;

- development of stakeholders' communication and interaction skills and competences.

At the company level, work intellectualization involves a new type of management. Company strategy and policy should be focused on intellectual capital generation, development, and valorization. Human resources, especially knowledge workers, should be the core of the company management. In the company, specific organizational structures, information systems, decision-making mechanisms, motivational approaches, etc. should be created in order to valorize the multiple qualities of intellectual work. A new type of organizational culture should be practised, in order to obtain maximum benefits from knowledge workers, and from their very productive intellectual capital.

The COVID-19 pandemic has helped people and organizations to understand better the importance and advantages of intellectual work, contributing to its increase in many organizations. 


\section{Internationalization of Activities}

Without any doubt, comprehensive internationalization is an essential megashift of the present times. This internationalization involves hundreds of states and independent territories, thousands of extremely diverse regions, with many strong particularities, which are not easy to perceive and take into consideration by socio-economic entities. All kinds of flows among states and regions - human, technical, managerial, commercial, financial, scientific, cultural, sporting, ecological, juridical, political, etc. - are permanently multiplying and accelerating. During the last few years, the speed of internationalization has increased - the digital revolution and telecommunications making major contributions - and, concomitantly, it has continued to diversify. Internationalization generates increasing globalization by involving more territories, fields of activities, organizations and individuals and by amplifying impacts of different natures at the level of mankind (Broadman, 2015; Ernst \& Young, 2015; Turcan, 2013; Wall, Rees, \& Minocha, 2011). Internationalization increases companies' access to different resources:

- information and knowledge

- raw materials

- labour forces

- new products and technologies

- machines and equipment

- energy

The opportunity of penetrating markets in other countries, despite their distance, is very important. Based on these elements, internationalization generates new business opportunities, either for existing companies or for new entrepreneurs and investors, in all countries. In the meantime, internationalization produces a lot of challenges and risks for companies, such as new, better and/or cheaper products and services from foreign producers and suppliers in local and national markets, new foreign investment in the company field, migration of the local labour force, proliferation of new competitive management, marketing, financial, etc. approaches, methods and techniques coming from other countries, fluctuation of exchange rates for major currencies, etc. In this context, all company activities change profoundly, starting with raw materials, energy, machine, and technology supply and finishing with the sale of products and services and incomes obtained. Organizational activities are more open to foreign markets, to technical and technological changes from other countries, to international financial and human resources, ecological trends, etc. 
Internationalization determines certain significant shifts at the company stakeholder level:

- modification of all company stakeholders' thinking, action, and behaviour under the impact of internationalization;

- increase in the level of direct and indirect influence of external company stakeholders from other countries, especially for mediumsized companies;

- enhancement of international interest from a large proportion of external and internal company stakeholders;

- increase of company stakeholders' potential and productivity because of their access to international information, knowledge, and other resources.

Company management should update their approaches, implementing innovations in all fields in order to be performant and to ensure the sustainability of the organization in such an international complex and dynamic environment.

Internationalization, in the context of the pandemic, faces numerous challenges. It has become more obvious that internationalization presents some important limitations, even disadvantages, for numerous countries and companies. In our opinion, internationalization will continue, but it should be remodelled in order to be more beneficial for all parties involved, for all stakeholders.

\section{Multiculturalization of the Labour Force}

The intense and heterogeneous multiculturalization represents one of the recent striking mutations that have developed in the society and in the economy. Multiculturalization means the establishment of human and work relations among individuals, groups and communities belonging to different national, regional and local cultures. The cultural differences among people from different areas are frequently large in terms of traditions, habits, rituals, mentalities, social value systems, communication methods, education, religion, social status, etc. All these generate specific and heterogeneous life visions, work approaches, individual and group values, decisional and actional approaches, individual and group behaviours, etc. Multiculturalization, from the organizational environment point of view, takes two forms:

- interstate multiculturalization, which deals with relations among people from different states, but who have a permanent residence in their home countries.

- intrastate multiculturalization, which includes people from different countries, but who live in the same state. 
Both types of multiculturalization strongly influence - although partially in a different manner - the configuration and especially the functionality of the organizational environment (Broadman, 2015; Ernst \& Young, 2015; Turcan, 2013; Wall, Rees, \& Minocha, 2011).

Multiculturalization influences companies by some inputs: companies have access to a cheaper, more or less skilled labour force, usually with a better salary-quality relationship. Also, employees with different cultures provide supplementary information and knowledge, which could represent new resources for the company. In companies, a multicultural labour force involves specific human resource management, certain modifications in internal and external communication, partial remodelling of the organizational culture and specific types of social responsibility. Quite often, multiculturalization determines certain changes in the approach of the domestic and international markets.

Multiculturalization influences company stakeholders in the following ways:

- increase in the number of company stakeholders with cultures other than the culture dominant in the company;

- modification to a certain extent of the company stakeholders' own culture under the impact of the multiculturalization of the organization's human resources and their relationships;

- development of new behaviours and of new decisions, approaches, and actions among company stakeholders because of the multicultural labour force involved;

- increase in the complexity of relationships with internal and external company stakeholders due to the multicultural influences involved.

The trade-off for companies from the multiculturalization of human resources could be large: decreased costs, especially in terms of the labour force; better access to markets, mainly in the areas where these employees come from; increase of the company's capacity to internationalize its activities, etc. The benefits of using multicultural individuals motivate the company's management to cope with the challenges and risks associated with working with human resources with different cultures from other countries or regions.

\section{Nanotechnologization and Biotechnologization}

Nanotechnologization and biotechnologization are two of the most spectacular megashifts that substantially modify global economic and social activities. Both regard, directly and indirectly, all fields of human activities (Brousseau \& Curien, 2007; Ciocoiu, Borisov, Dobrea, Burcea, \& Târțiu, 2012; Day \& Schoemaker, 2016; Markoff, 2016). Nanotechnologization elaborates and uses technologies at the atom level, creating new intelligent 
raw materials and small-size equipment and machines, with high yield and productivity, much higher than those achieved previously.

Biotechnologization, through genetic changes at the life cell level, determines the substantial improvement of animal breeds and plant varieties, generating very high production on the surface unit and on the animal capita (Brousseau \& Curien, 2007).

In companies - especially in industrial ones - nanotechnologization provides many new inputs: raw materials, new smart technologies, products, knowledge and miniaturized equipment and machines. In agriculture and in food industry companies, biotechnologization offers as inputs new technologies, products, raw materials, animal breeds, plant varieties, equipment, etc. Many of the company activities are changing because of these new inputs. The most frequently found changes are focused on production, $\mathrm{R} \& \mathrm{D}$, commercial activities, and the training of human resources. Changes in company inputs and activities generate much better outcomes at the organization level: higher quality of products and services, more competitive products, increased company sale prices and income, development of a competitive brand, higher prices of company shares, etc.

Nanotechnologization and biotechnologization determine some significant shifts at the level of company stakeholders. Among these, we mention the following:

- major changes in internal stakeholders' work, especially those involved in production, $\mathrm{R} \& \mathrm{D}$, and human resources, in order to implement nanotechnologies and biotechnologies;

- appearance of new external stakeholders, who provide the nanotechnologies, biotechnologies, and all equipment and services necessary to use them in the company;

- partial modification of the relationships of company managers with the majority of external stakeholders, in order to fully valorize the beneficial effects of the nanotechnologization and biotechnologization.

In order to achieve all these changes generated by nanotechnologization and biotechnologization, companies' management should elaborate and implement specific strategies and policies and update the management of all fields mentioned above - R\&D, production, commercial, and human resources. By performing these managerial operations, companies' outputs are better - higher-quality product, increased productivity and yield, lower unit cost - thereby obtaining competitive advantage and sustainability.

We appreciate that both nanotechnologization and biotechnologization are only in the beginning phase of their development. In the next 
few years, nanotechnologization and biotechnologization will produce many more outstanding innovations, which will have more impact, and in ways difficult to anticipate now, on companies and on numerous other socio-economic entities. Company management should be very anticipative, productive, and innovative in order to face the new challenges and opportunities generated by nanotechnologization and biotechnologization. It will manage based on new business models, involving more and diversified smart stakeholders, with rich top knowledge and using high-quality intellectual capital.

\section{Comprehensive Networking in the Society and the Economy}

Society and economy networking has grown fast in the last few decades, reflecting the structuring of an increasing number of business environment components as networks. Social practice reveals that network - structured as clusters, hubs, technopolis, technological platforms, network companies, commercial chains, multinational companies, holdings, federations, professional, scientific, sporting, etc. associations - are more frequent and more important in all domains. Networking has developed as an organizational feedback to the division of labour, deepening in the society and economy, structured in numerous components, many of them small in size, and frequently specialized. As a consequence, efficient and permanent work with other entities becomes more and more difficult. Networking is trying to overcome the limitations and difficulties associated with small-sized and/or specialized entities, concomitantly with better valorization of the new opportunities generated by the knowledge revolution. Informatization, digitalization, internationalization, nanotechnologization, etc. are providing powerful information, knowledge, communication, human, and technical support for performant networking.

The large proliferation of networks and the increase of their importance and impact are reflected in the emergence of a new profession, "netocrat", i.e. people who control the networks.

The main inputs generated by these networks in companies are: easier and faster access to suppliers, clients, production partners, financial entities, consultants, trainers, investors, etc.; more access to information and knowledge about network components; more interconnectivity with external company stakeholders and easier collaboration with them.

Company activities are changing to a certain extent in order to be able to communicate and work with other network components. Quite often a company develops its supply chain and improves customer relationships. Participation of the company in a network involves significant changes in managerial decisions, actions and behaviours, in order to respond to the specific requirements of the networks in which 
the company is integrated, and to get "de facto" network benefits. Company management could also develop easier, performant specialized systems for important domains. The most frequently developed are supply chain management (SCM) and client relationship management (CRM). Sometimes it is beneficial to build a matrix structure in the company.

The business model for a company integrated in networks should be remodelled, transforming the enterprise from being productdriven to networking-driven. This helps the company to maximize the advantages of being a network member: higher-rated company brand, better-quality products and services, superior position of the company in the market, and more profitable relationships with external stakeholders (Becerra, 2017; Inkpen \& Tsang, 2016; Jarvenpaa \& Välikangas, 2014; McIntyre \& Srinivasan, 2017; Perry-Smith \& Mannucci, 2017).

The present intensification of the comprehensive networking in the economy and the society has some important influences on company stakeholders:

- development of the co-working and the relationships of the company stakeholders, especially of the external stakeholders;

- increase of the intellectual capital of the company stakeholders, mainly of the relational capital;

- enhancement of the stakeholders' capacity to integrate the company's activities in the business and social environment, and to be engaged more successfully in the enhancement of performances.

The proliferation of networks - both business and social - fosters and develops new ecosystems in the economy and contributes to the fast development of a collaborative and shared economy (Lichtenthaler, 2016).

In the context of the COVID-19 pandemic, networking reveals two contradictory faces:

- the virtual network based on working online has been less affected by the effects of the COVID-19 pandemic and it helps organizations to solve many problems, decreasing the risk of people infection.

- the physical network has been blocked or decreased notably because of restrictions associated with the fight against the pandemic.

Without any doubt, the COVID-19 pandemic has stimulated the development of virtual networking inside and outside organizations, contributing to the increase of the degree of networking in society and the economy. 


\section{Sustainable Ecologization}

Many analyses reveal that the environmental protection against the negative effects of human activities (primarily of economic activities), the more efficient and equitable use of non-renewable natural resources and the resetting of ecological equilibriums at the world, continental, and regional level represent the main components of ecologization. All these processes mean new inputs, restrictions, and outputs for numerous types of organizations. For the majority of them, ecologization determines significant changes in strategies, policies, systems, mechanisms, activities, and outputs.

Sustainability is a new dimension of ecologization developed in the last few decades. Sustainable ecologization means the approach of ecologization in a long-run perspective and providing the necessary resources for its implementation. Sustainable ecologization determines the amplification of the requirements and pressures on all types of organizations. Notwithstanding, sustainability is essential for the survival of mankind and for its continued development, valorizing the huge opportunities generated by the knowledge revolution. On the other hand as Brown, Adams, Larsen, and Roney (2015) have outlined - there is a big danger of an ecological decline and, as a consequence, of economic and social decline.

In all countries, in order to achieve sustainable ecologization, special laws and other regulations have been adopted regarding environmental protection, health security for human resources and ecostandards, in accordance with the numerous international agreements and protocols in this field.

At the company level, there are substantial changes in inputs, concerning: prohibition of certain raw materials and technologies; mandatory characteristics for many raw materials, technologies, machines, equipment, etc.; generation and use of energy; production, use, storing, and reuse of waste; special taxes and penalties for the utilization of pollutant substances; higher limits regarding carbon dioxide, and other noxious emissions.

Many of company activities should be changed in order to respect the legislation and to be able to utilize profitably the new inputs. The most frequent changes affect production, supply, sale, R\&D activities, storage, human resources security and transportation. Sometimes, especially in industry, new activities should be organized in companies for waste storage, reuse of waste, waste transportation, environmental and health protection, etc. Previous requirements and changes involve significant shifts in company management strategies, policies, systems, methods, approaches, operations, etc.

In company outputs, we can see two categories of changes. The first refers to the making of ecological products and services, reduction of 
noxious waste, reuse of waste, and better protection of the company and local environment. The second category, regarding economic aspects, are increased costs of raw materials, technologies, machines, and supplementary investments or decreased profits. This category has been neglected to a certain extent during the COVID-19 pandemic, because of the emergence of new priorities and restrictions.

The ecologization megashift also influences company stakeholders in several ways:

- rise of the new category of external stakeholders, like local communities, "ecological" NGOs, protection agencies focused on the ecological field, which promote requirements, rules, standards, etc. in order to preserve and protect the ecological environment;

- development of new approaches at the level of company stakeholders through which sustainable ecologization is promoted;

- building of some special kind of stakeholder networking focused on waste and on the circular economy.

Companies' and stakeholders' compliance with the ecological requirements and standards is necessary for company survival and sustainable development, for population security and health, and for the protection of the local, national, continental, and global environment.

\section{Intensification and Diversification of State Intervention}

In recent decades, state interventions in the society and economy have increased dramatically at the national, regional, and world level. The COVID-19 pandemic has increased state intervention at a high level, never previously seen during peacetime. State interventions from the point of view of their scope can be divided into three categories:

a State intervention at the country level, usually dealing with the preservation and increase of the business environment functionality and predictability, with decent life standards and social peace. These interventions were increased during the 2009-2011 world economic crisis, which continues in many countries, attaining a peak during COVID-19 pandemic.

b State intervention at continental level, where there are multi-state systems of international economic integration. The European Union is the best such example. This type of state intervention is directed at the development of the regional environment, enabling economic and social development and valorizing at a higher level the specificity of each country involved and their complementarities.

c Global intervention, usually through international organizations, whose members comprise all or a large number of world states. 
The UN, ILO, IMF, and WB are the most comprehensive and bestknown such types of international bodies. A major role is also played by certain groups from the most powerful and influential states, like the G7, G20, OECD, and NATO. Their interventions at global, continental, regional, or national level usually deal with the prevention and/or elimination of crises and/or major political, economic, military and social dysfunctionalities, or the improvement of the economic and societal environment and/or development at the international level.

The global societal crisis generated by the COVID-19 pandemic necessitates concomitantly these three types of state interventions. Analysis reveals that state interventions influence companies mainly in two ways:

- Modifying the entire business environment. The business environment, from the point of view of companies' activities and performance, could be enabling, permissive, or unfavourable. In an enabling environment, it is easy to create new companies and, for existing enterprises, there are good conditions in order to be performant and sustainable. Normally, all state interventions should be focused on the development of an enabling business environment. Unfortunately, in real life, sometimes state interventions damage the business environment with very negative effects on the business and society;

- Changing only some components of the business environment. This happens when a state intervention is focused on a specific field or domain, like fiscality, labour force, industry, agriculture, etc. In this case, company activities are impacted, positively or negatively, only partially.

It is very important that every state intervention, through strategies, policies, laws, administrative regulations, standards, etc., is preceded by ex-ante impact analysis, in order to avoid negative effects on the economy and society and to contribute to developing an enabling environment for all kinds of companies.

Changes in the business environment caused by state interventions have multiple impacts on companies. The most frequent impacts of state interventions on companies relate to:

- taxes and fees

- investment conditions

- environmental protection

- work security

- access to certain resources

- exchange rates 
- utilities tariffs

- storage and use of waste

All these elements determine changes in company inputs, activities, and outputs.

Company management should carefully analyze and take into consideration such state interventions, should prepare and operate all necessary changes in order to make them profitable for the company, or at the very least - be tolerable well, without decreasing the organization's competitive capacity and sustainability.

State interventions influence company stakeholders mainly in the following ways:

- Modification to a certain extent of the relationships between the company and its stakeholders, because of the changes in taxes, fees, security requirements, investment conditions, etc.

- Facilitation of the appearance and/or development of new company stakeholders, like investors, suppliers, distributors or customers, when state interventions enable investments, increased production and sales, as well as exports and imports, etc.

- Contribution of the elimination or reduction of certain company stakeholders when state taxes, fees, tariffs and requirements regarding environmental protection, investments, etc. demotivate them or make their activities non-profitable.

In our opinion, based on previous tendencies, in the future state interventions will be more intense and more varied in terms of their content and ways to implement them. These state interventions will continue to be predominantly strategic, but the operational dimension will increase too, being essential for social, economic, ecological, military, etc. equilibrium at the regional, national, and international level, for sustainable and peaceful development. State feedbacks in the COVID-19 pandemic context confirms these predictions.

\section{Development of the Powerful Educational-Formative Dimension}

The quality of human resources represents the determinant element for the manifestation of all the above-mentioned business environment trends. All types of evolutions - economic, technical, political, scientific, ecological, managerial, etc. - are the result of human thinking, decisions, actions, and behaviours. The last few decades have been characterized by comprehensive and profound progress regarding human resource education and training. Access of the most part of population to the education, and its substantial improvement, 
becoming more pragmatic, innovative and entrepreneurial, provide higher quality human resources, more dynamic and productive. Education, training, and lifelong learning have become conditional for organizations' survival and performance, for the proper functioning of society and for competitive development. Numerous researches and studies have proved that education and training investments are the most productive ones. For this reason, in the future education and training will intensify in order to provide a labour force capable of assimilating and valorizing knowledge, the most productive resource of the knowledge-based economy and society. This trend has, and will continue to have, major positive effects on all types of organizations' activities and performance.

The influence of human resources on a company is decisive in many respects. First, the employees represent one of the most important inputs in the enterprise. The skills, knowledge, methods, techniques, creativity, engagement, work capacity, behaviour, etc. of employees determine the effectiveness and efficiency of every resource in the company (raw materials, machines, equipment, buildings, cash, patents, etc.). Second, the company activities' content and results are substantially influenced by the characteristics of the human resources employed. The quality and the cost of every task and job accomplished in the company are largely impacted by the qualification, creativity, and efforts of the employees involved. A company's human resources make a major contribution to all indicators of the enterprise's performance - from the labour productivity to the size of turnover and profit. Employees contribute decisively to the company's capacity to generate competitive advantage and competitiveness. For this reason, in numerous companies, the training and development of human resources are a priority, with the enterprise management allocating a large amount of money to this. Many companies are already learning organizations and the role of learning becomes essential. According to a recent study (Bailey, Reeves, Whitaker, \& Hutchinson, 2019), in the coming decade, companies will increasingly need to compete on the rate of learning. To unlock the learning potential of new technologies, leaders need to reinvent the enterprise as a next-generation learning organization (Lesser, Reeves, Whitaker, \& Hutchinson, 2018). Every organization needs to look at learning as a core competency (Daugherty, Wilson, \& Michelman, 2019).

Development of the powerful educational-formative dimension in the society determines certain significant changes at the level of company stakeholders:

- Increased level of education, knowledge, and competences of company stakeholders; 
- Amplification of the stakeholders' capacity to understand and to analyze events, individual, and organizational changes and to have innovative undertakings;

- Facilitation of the communication and networking of the company stakeholders inside and outside the organization.

Transition to the knowledge-based economy and society, and digitalization of the main content of the present development, will be permanently associated with the tendency to increase education, training, and lifelong learning, which means human resources with more and a higher level of knowledge. Training and educational processes will take into consideration the rapid changes in technologies, including artificial intelligence, and machine and mobile learning. Already some specialists have formulated new ways to structure education and to use education technology (Ghemawat, 2017; Lyons, 2017; Pyöriä, Ojala, Saari, \& Järvinen, 2017).

In the context of the COVID-19 pandemic, decisions and actions regarding education and training should be correlated with those focused on the preservation of people's physical and mental health.

\section{Multidimensional Remodelling of Markets}

Markets represent a major component of the business environment, which has changed rapidly and substantially during the last few decades. The largest modifications have occurred in the market for products and services, the labour market, and the financial market. The main changes are:

- comprehensive informatization, more than half of the world population being already connected online (Gada, 2016; Hoffmann, Lavie, Reuer, \& Shipilov, 2018; Lerider, 2017);

- accelerated digitalization;

- telecommunication expansion;

- business internationalization;

- business and social networking;

- global value chain development;

- population higher level of education;

- improved standard of living;

- proliferation of new types of work organization (hubs, clusters, technological platforms, etc.);

- trade barriers lowered at international, regional, and national level, with some fluctuations in recent years.

Under the impact of the COVID-19 pandemic, these changes have been modified to a certain extent. Some of them, like accelerated digitalization 
and telecommunication expansion, have developed faster. Others - like global value chain development, standard of living enhancement, population higher level of education, and lowering of trade barriers - have reduced or even stopped increasing.

Today's markets present many new characteristics compared with the "classical" markets: rapid proliferation of e-commerce, increased market fluidity, building of very large, and powerful networks of suppliers and clients, proliferation of concurrence between producers network stakeholders, very high weight of internationalized trade in the global trade, appearance of a new type of concurrence - concurrence based on collaboration and others. Market changes contribute to the design of new business models, which causes multiple shifts in all company activities.

The present very developed and functional markets make it possible for companies to have more, faster and lower-cost inputs - raw materials, products, services, labour force, energy, money, etc. The importance and the impact of company activities that deal with markets marketing, supply, import, export, and sale - are constantly increasing. Other enterprise activities - production, $\mathrm{R} \& \mathrm{D}$, finance, investment, etc. - will be more oriented to, and connected with, the market dynamic.

Company management should be increasingly open to the market evolution, elaborating and implementing innovative commercial strategies, policies, and mechanisms. Supply chain management (SCM) and Customer Relationship, Management (CRM) will be implemented in more companies, especially large and medium-sized ones. Better company access to markets usually increases the size and the speed of product sales, both being good premises to enlarge the enterprise's turnover and profit. Concomitantly, the company needs to invest in order to digitalize and internationalize activities and to agree to share with network components some of the commercial costs and company profits.

In the near future markets will increase the speed and size of the impact on companies, because of continued and fast mutations that happen to them. Among these, we mention the following: trading using digital identity, smart contracts (Lerider, 2017), a neuromarketing approach (Hsu, 2017), extension of hub firms, which control the access of billions of mobile consumers connected by all kinds of products and services providers (Iansiti \& Lakhani, 2017), proliferation of competing stakeholder networks (Freeman, Harrison, Wicks, Parmar, \& De Colle, 2010), transition to the so-called "era of consumers", proliferation of regional and continental digital markets, like the Digital Single Market in the European Union, and others.

Multidimensional remodelling of the markets influences company stakeholders mainly in the following ways:

- increase of the impact of the market evolutions on company stakeholders' decisions, actions, and behaviours; 


\section{Contextual Main Changes and Influences}

- developing networks of suppliers, intermediaries, and clients;

- transition from concurrence between producers to concurrence of the producers' networks.

Rapid, complex, and sometimes unexpected changes in the categories of markets - like those provoked by the COVID-19 pandemic - will significantly increase the opportunities, challenges, and threats for companies, involving for their management fast and innovative feedback integrated in a long-term sustainable vision.

Of course, the tendencies formulated by us, using the results of many previous researches from all over the world, are neither exhaustive nor debatable. We have presented them because we believe that they could to a large extent - be used as major points in order to facilitate the understanding and utilization of the essential evolutions of the changing business environment for management decisions, actions, and behaviours, ensuring the company's survival and competitiveness. These megashifts could be a very good framework helping to identify and cultivate performant relations with the organization's stakeholders and their management.

\section{Short Synthesis of the Influences of Megashifts on a Company and Its Stakeholders}

Together, the contextual trends briefly presented in the previous sections have many significant and complex influences on companies. We try to synthesize and group them into two categories:

a Influences on the company as an entity, as an open system, integrated in the environment, mainly in the business environment. In Figure 3.3, we indicate these influences.

b Influences on company stakeholders. We enumerate these in Figure 3.4.

There are close connections between a company's influences of contextual changes on the one hand and stakeholders' influences on the other. Practically, they are interwitted, growing mutually.

Company management, in order to be performant, needs to understand, analyze, and take into consideration the main contextual company and stakeholder changes, in an innovative vision and pragmatic approach. Of course, special attention should be paid to the recent changes in the business environment under the influence of the COVID-19 pandemic. Many specialists have already conducted very interesting and useful analysis, proposing new concepts, approaches, and methods (Chaturvedi, Dey, \& Singh, 2020; Chima \& Gutman, 2020; Dykes, Hughes-Morgan, Kolev, \& Ferrier, 2020; Heichler, 2020; Kaplan, 2020; Levenson, 2020; 


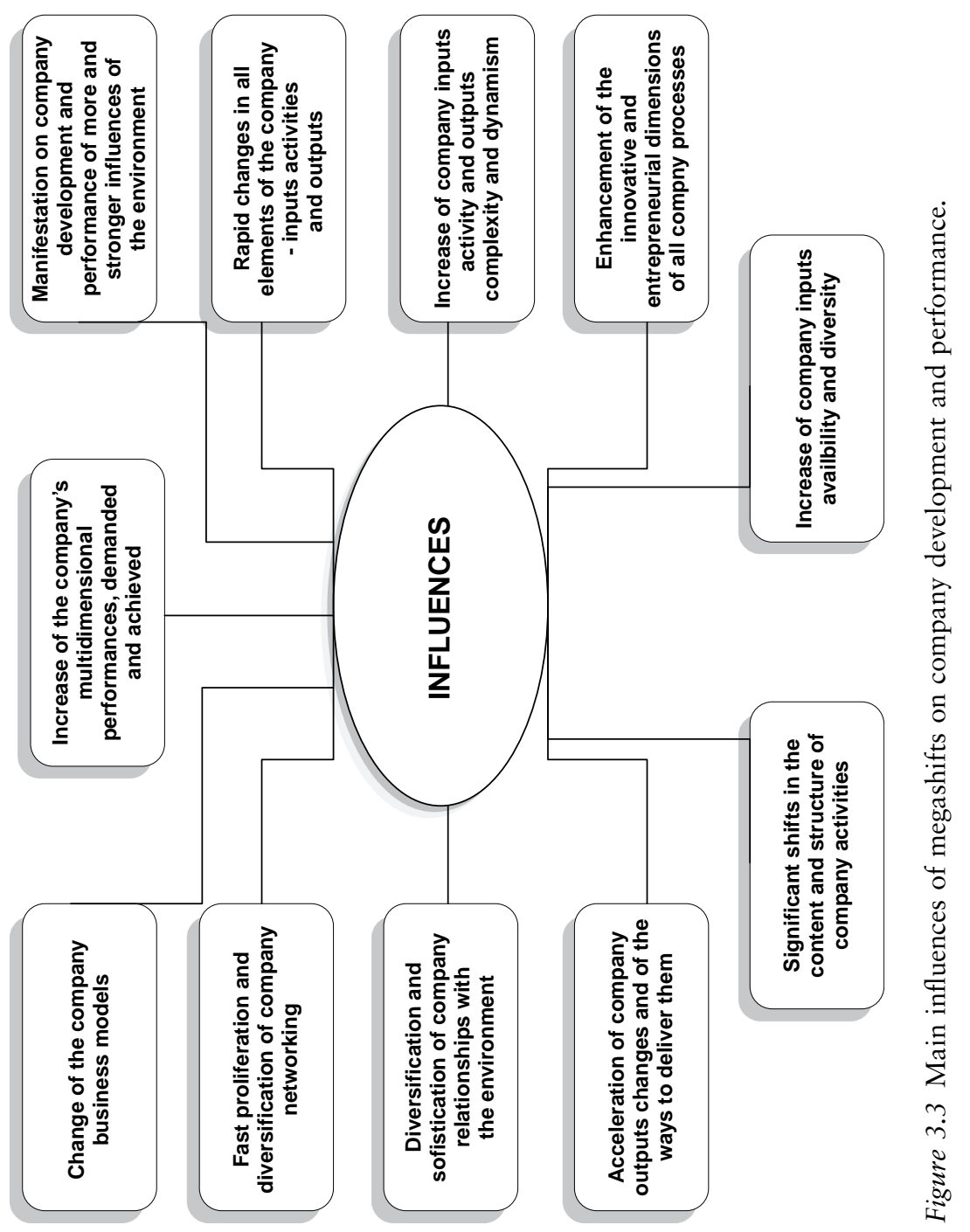




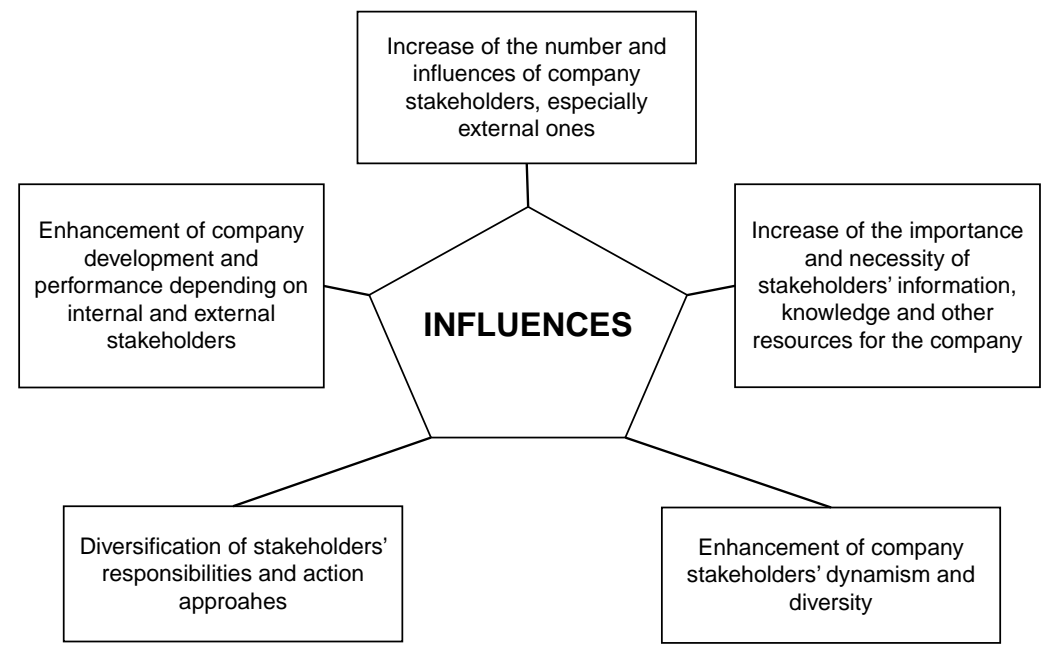

Figure 3.4 Major influences of megashifts on company stakeholders.

Mokyr, 2020; Narayandas, Hebbar, \& Li, 2020; Radjou, 2020; Romeo, Moukanas, \& Rung, 2020).

In the following chapters, we will present elements that could be useful in rethinking and remodelling company management in accordance with the present and future megashifts in the economy and society.

\section{References}

Attali, J. (2007). Une brève histoire de l'avenir. Paris, France: Fayard.

Bailey, A., Reeves, M., Whitaker, K., \& Hutchinson, R. (2019, April 5). The company of the future: Winning the '20s. Retrieved from https:// www.bcg.com/publications/2019/company-of-the-future.aspx

Becerra, J. (2017, March 14). The digital revolution is not about technology: It's about people. World Economic Forum. Retrieved from https://www.weforum. org/agenda/2017/03/the-digital-revolution-is-not-about-technology-it-s-aboutpeople

Bennett, N., \& Lemoine, G. J. (2014). What VUCA really means for you. Harvard Business Review, 92(1-2), 27-28.

Birkinshaw, J., Hamel, G., \& Mol, M. J. (2008). Management innovation. Academy of Management Review, 33(4), 825-845. doi:10.5465/amr. 2008.34421969

Brătianu, C. (2015). Organizational knowledge dynamics: Managing knowledge creation, acquisition, sharing, and transformation. Hershey, PA: IGI Global. doi: 10.4018/978-1-4666-8318-1

Broadman, H. G. (2015, March 30). Welcome to globalisation 2.0. Or is it 3.0? Forbes. Retrieved from https://www.forbes.com/sites/harrybroadman/2015/ 03/30/welcome-to-globalization-2-0-or-is-it-3-0/\#360e603f65a1 
Brousseau, E., \& Curien, N. (2007). Internet and digital economics: Principles, methods and applications. Cambridge, UK: Cambridge University Press. doi: 10.1017/CBO9780511493201

Brown, L. R., Adams, E., Larsen, J., \& Roney, M. (2015). The great transition: Shifting from fossil fuels to solar and wind energy. New York: W.W. Norton \& Company.

Burkus, D. (2013). Innovation isn't an idea problem. Harvard Business Review. Retrieved from https:/hbr.org/2013/07/innovation-isnt-an-idea-proble

Chaturvedi, H., Dey A. K., \& Singh, N. (2020). Coping with COVID-19. Global Focus the EFMD Business Magazine. Retrieved from https://www.globalfocus magazine.com/coping-with-covid-19/

Chima, A., \& Gutman, R. (2020). What it takes to lead through an era of exponential change. Harvard Business Review. Retrieved from https://hbr.org/ 2020/10/what-it-takes-to-lead-through-an-era-of-exponential-change

Christensen, C. M., Raynor, M. E., \& McDonald, R. (2015). What is disruptive innovation? Harvard Business Review, 93(12), 44-53.

Ciocoiu, N. C., Borisov, D. L., Dobrea, R. C., Burcea, Ș. G., \& Târţiu, E. V. (2012). Modern approaches in exploring the link between digital economy and waste management. Bucuresti, Romania: ASE Publishing House.

Daugherty, P. R., Wilson, H. J., \& Michelman, P. (2019). Revisiting the jobs artificial intelligence will create. MIT Sloan Management Review. Retrieved from https://sloanreview.mit.edu/article/revisiting-the-jobs-artificial-intelligencewill-create/?gclid=Cj0KCQjw-_j1BRDkARIsAJcfmTFWo5

DuagUAIhgQJshFIhDY9-el77zsx1903xSTxV2

NbIeWLrEvsWwaApJxEALw_wcB

Day, G. S., \& Schoemaker, P. J. H. (2016). Adapting to fast-changing markets and technologies. California Management Review, 58(4), 59-77. doi:10.1525/ cmr.2016.58.4.59

Dykes, B. J., Hughes-Morgan, M., Kolev, K. D., \& Ferrier W. J. (2020). Responding to crises with speed and agility. MIT Sloan Management Review. Retrieved from https://sloanreview.mit.edu/article/responding-to-crises-withspeed-and-agility/

Ernst \& Young. (2015). Redrawing the map: Globalisation and changing the world of business. Retrieved from https://www.slideshare.net/ManagementThinking/redrawing-the-map-globalization-and-the-changing-world-ofbusiness

Freeman, R. E., Harrison, J. S., Wicks, A. C., Parmar, B. L., \& De Colle, S. (2010). Stakeholder theory: The state of art. New York: Cambridge University Press.

Gada, K. (2016, June 16). The digital economy in 5 minutes. Forbes. Retrieved from https:/www.forbes.com/sites/koshagada/2016/06/16/what-is-the-digitaleconomy/\#2088cd737628

Garrow, V., \& Varney S. (2015). Organisation design in a VUCA world. A paper from HR in a disordered world: IES perspectives on HR 2015. Retrieved from http://www.employment-studies.co.uk/system/files/resources/files/mp105.pdf

Ghemawat, P. (2017). Strategies for higher education in the digital age. California Management Review, 59(4), 56-78. doi:10.1177/000812561 7717706 
Griffin, R. W. (2012). Management: Principles and practices. Mason, $\mathrm{OH}$ : South-Western Cengage Learning.

Grossman, R. (2016). The Industries that are being disrupted the most by digital. Harvard Business Review. Retrieved from https://hbr.org/2016/03/theindustries-that-are-being-disrupted-the-most-by-digital.

Hamel, G. (2006). The why, what, and how of management innovation. Harvard Business Review, 84(2), 72-84.

Heichler, E. (2020). Seize the moment. MIT Sloan Management Review. Retrieved from https://sloanreview.mit.edu/article/seize-the-moment/?og=Fall $+2020+$ Issue+Horizontal

Hoffmann, W., Lavie, D., Reuer J. J., \& Shipilov, A. (2018). The interplay of competition and cooperation. Strategic Management, 39(12), 3033-3053. doi: $10.1002 /$ smj. 2965

Hsu, M. (2017). Neuromarketing: Inside the mind of the consumer. California Management Review, 59(4), 5-22. doi:10.1177/0008125617720208

Iansiti, M., \& Lakhani, K. R. (2017). Managing our hub economy: Strategy, ethics, and network competition in the age of digital superpowers. Harvard Business Review, 95(5), 84-92.

Inkpen, A. C., \& Tsang, E. W. K. (2016). Reflections on the 2015 decade awardsocial capital, networks, and knowledge transfer: An emergent stream of research. Academy of Management Review, 41(4), 573-588. doi:10.5465/amr. 2016.0140

Jarvenpaa, S. L., \& Välikangas, L. (2014). Opportunity creation in innovation networks: Interactive revealing practices. California Management Review, 57(1), 67-86. doi: 10.1525/cmr.2014.57.1.67

Kaplan, S. (2020). Why social responsibility produces more resilient organizations. MIT Sloan Management Review. Retrieved from https://sloanreview.mit.edu/ article/why-social-responsibility-produces-more-resilient-organizations/

Lerider, M. (2017, August 11). What is NEO Smart Economy? Retrieved from https://medium.com/@MalcolmLerider/what-is-neo-smart-economy-381 a4c6ee286

Lesser, R., Reeves, M., Whitaker, K., \& Hutchinson, R. (2018, December 14). A leadership agenda for the next decade: Winning the '20s. Retrieved from https://www.bcg.com/publications/2018/winning-the-20s-leadership-agendafor-next-decade.aspx

Levenson, A. (2020). A long time until the economic new normal. MIT Sloan Management Review. Retrieved from https://sloanreview.mit.edu/article/along-time-until-the-economic-new-normal

Lichtenthaler, U. (2016). Six principles for shared management: A framework for the integrated economy. Journal of Business Strategy, 37(4), 3-11. doi: 10.1108/JBS-03-2015-0029

Lyons, R. K. (2017). Economics of the ed tech revolution. California Management Review, 59(4), 49-55. doi:10.1177/0008125617717708

Markoff, J. (2016, January 7). Un système d'archivage venu de l'AND. Courrier International, 1314, 37-38.

McIntyre, D. P., \& Srinivasan, A. (2017). Networks, platforms, and strategy: Emerging views and next steps. Strategic Management Journal, 38(1), 141-160. doi: $10.1002 / \mathrm{smj} .2596$ 
Mokyr, J. (2020). Why our knowledge economy can survive the new age of pestilence. MIT Sloan Management Review. Retrieved from https:// sloanreview.mit.edu/article/why-our-knowledge-economy-can-survive-thenew-age-of-pestilence/

Naqvi, A. (2014, April 25). Cities, not countries, are the key to tomorrow's economies. Financial Times. Retrieved from https://www.ft.com/content/0221 bb6e-cb9d-11e3-8ccf-00144feabdc0

Narayandas, D., Hebbar, V., \& Li, L. (2020). Lessons from Chinese companies' response to Covid-19. Harvard Business Review. Retrieved from https:// hbr.org/2020/06/lessons-from-chinese-companies-response-to-covid-19

Nicolescu, O., Nicolescu, C., Bontea, A., Urîtu, D., Corcodel, S.-F., Samek, D., et al. (2019). Carta alba a IMM-urilor din Romania 2019. Bucuresti, Romania: Editura Pro Universitaria.

Nicolescu, O., Popa, I., Nicolescu, C., \& Stefan, S. C. (2019). Starea de sanatate a managementului din Romania in 2018. Bucuresti, Romania: Pro Universitaria.

Perry-Smith, J. E., \& Mannucci, P. V. (2017). From creativity to innovation: The social network drivers of the four phases of the idea journey. Academy of Management Review, 42(1), 53-79. doi:10.5465/amr.2014.0462

Pisano, G. P. (2015). You need an innovation strategy. Harvard Business Review, 93(6), 44-54.

Pyöriä, P., Ojala, S., Saari, T., \& Järvinen, K-M. (2017). The millennial generation: A new breed of labour? Sage Open, 7(1), 1-14. Retrieved from https://journals.sagepub.com/doi/pdf/10.1177/2158244017697158 10.1177/ 2158244017697158

Radjou, N. (2020). The rising frugal economy. MIT Sloan Management Review. Retrieved from https://sloanreview.mit.edu/article/the-rising-frugal-economy/

Rifkin, J. (2016, January 14). The 2016 world economic forum misfires with its fourth industrial revolution theme. Retrieved from https://www.huffington post.com/jeremy-rifkin/the-2016-world-economic-f_b_8975326.html

Romeo, J., Moukanas, H., \& Rung, G. (2020). The age of accelerating strategy breakthroughs. MIT Sloan Management Review. Retrieved from https:// sloanreview.mit.edu/article/the-age-of-accelerating-strategy-breakthroughs/

Schweer, D., \& Sahl, J. C. (2017). The digital transformation of industry: The benefit for Germany. In F. Abolhassan (Ed.), The drivers of digital transformation. Management for professionals (pp. 23-31). Cham, DE: Springer. doi:10.1007/978-3-319-31824-0_3

Turcan, R. V. (2013). The philosophy of turning points: A case of deinternationalization. In T. M. Devinney, T. Pedersen \& L. Tihanyi (Eds.), Philosophy of science and meta-knowledge in international business and management (pp. 219-235). Bingley, UK: Emerald Group Publishing Limited. doi:10.1108/S1571-5027(2013)0000026014

Unruh, G., \& Kiron, D. (2017). Digital transformation on purpose. MIT Sloan Management Review. Retrieved from https://sloanreview.mit.edu/article/ digital-transformation-on-purpose/

Wall, S., Rees, B., \& Minocha, S. (2011). International Business (4th ed.). London: Pearson Education Limited. 